\title{
GREEN SYNTHESIS OF COUMARINYL SCHIFF BASES UTILIZING CHOLINE CHLORIDE-BASED DEEP EUTECTIC SOLVENTS
}

\section{Lončar Mirjana, Molnar Maja}

Josip Juraj Strossmayer University of Osijek, Faculty of Food Technology Osijek,

Department of Applied Chemistry and Ecology, Franje Kuhača 20, HR-31 000 Osijek, Croatia
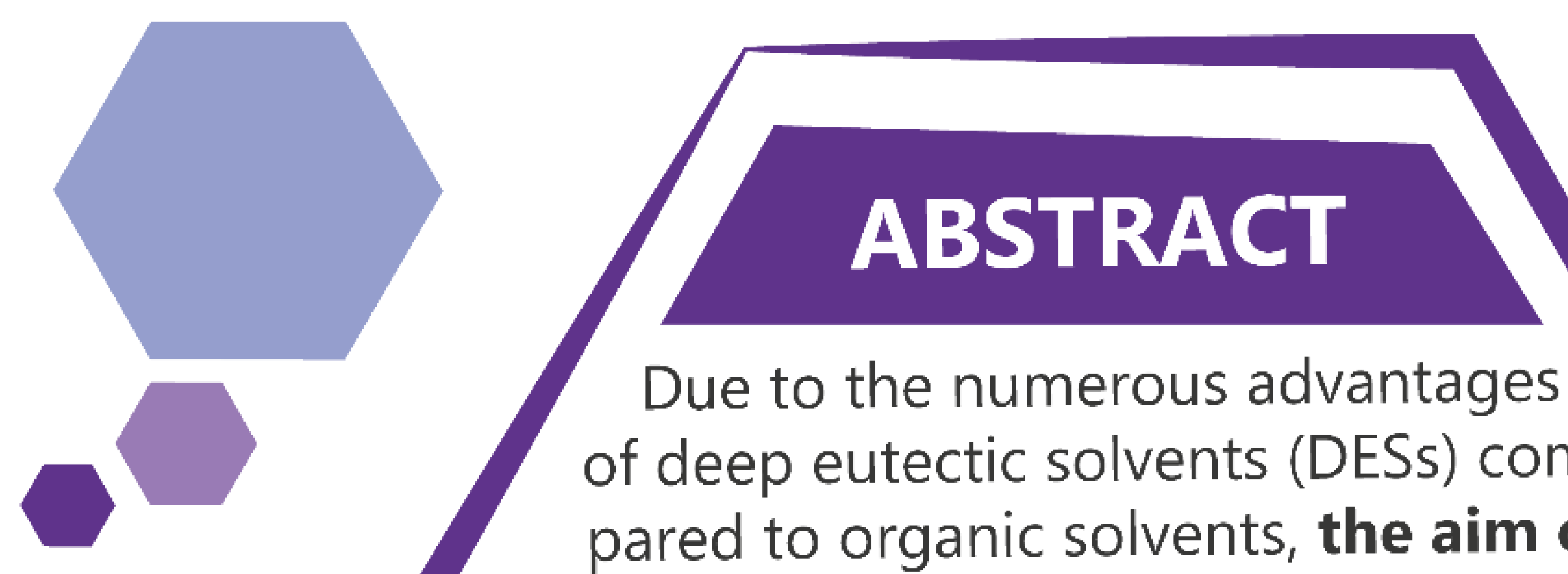
pared to organic solvents, the aim of this study was to synthesize coumariny Schiff bases utilizing ChCl-based DESs as a reaction media and a catalyst, as well. We applied an environmentally friendly ap

proach, utilizing a solvent made of biodegradable components, with low toxicity and vapor pres low toxicity and vapor pres-

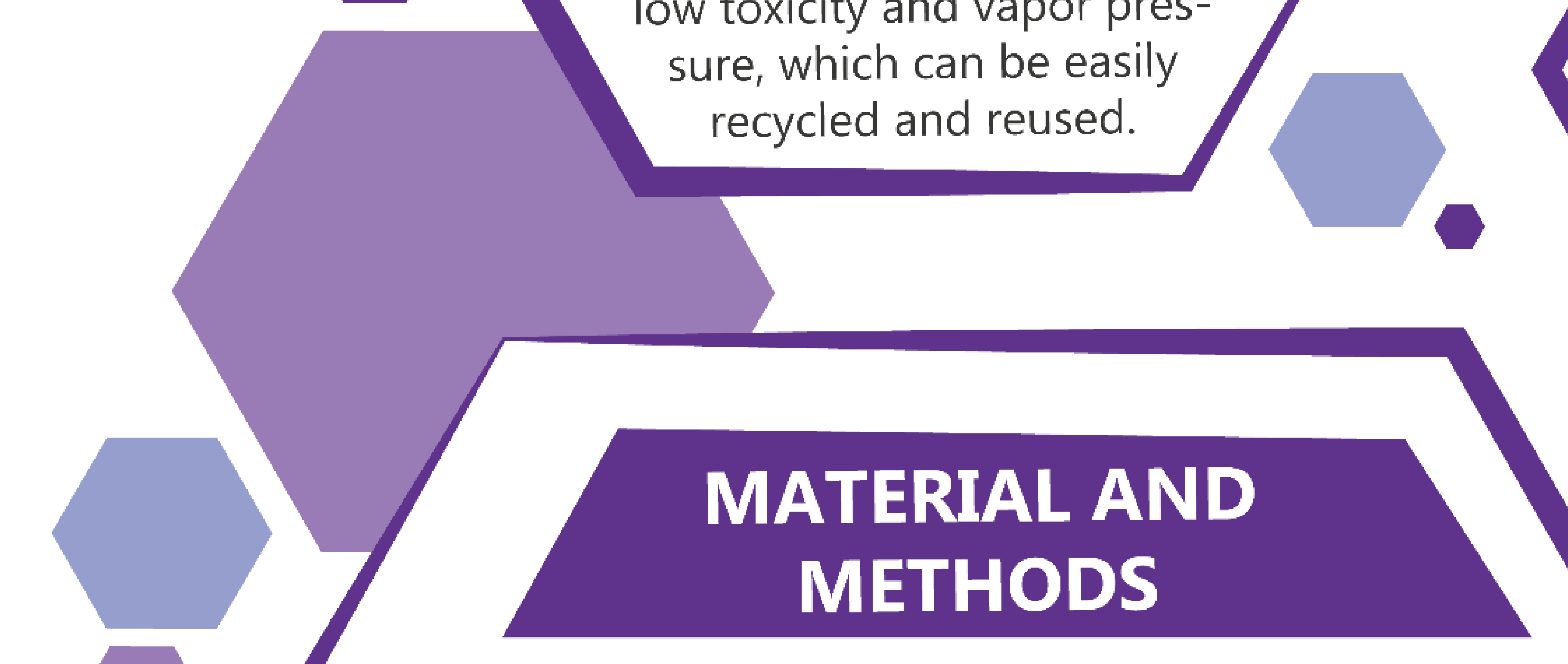

Firstly, we prepared 2-cyanoacetohydrazide (3) from hydrazine hydrate (1) and ethyl cyanoacetate (2). Schiff bases (5a-h) were prepared by refluxing equimolar amount of 2-cyanoacetohy drazide (3) and different aldehydes (4a-h), in ethanol, with 2-3 drops of acetic acid. Afterwards, the synthesis of coumarinyl Schiff bases (7a-h) was performed in ChCl:urea (1:2) DES, by mixing the equimolar amounts of compounds $\mathbf{5 a - h}$ and 2,5-dihydroxybenzaldehyde (6).
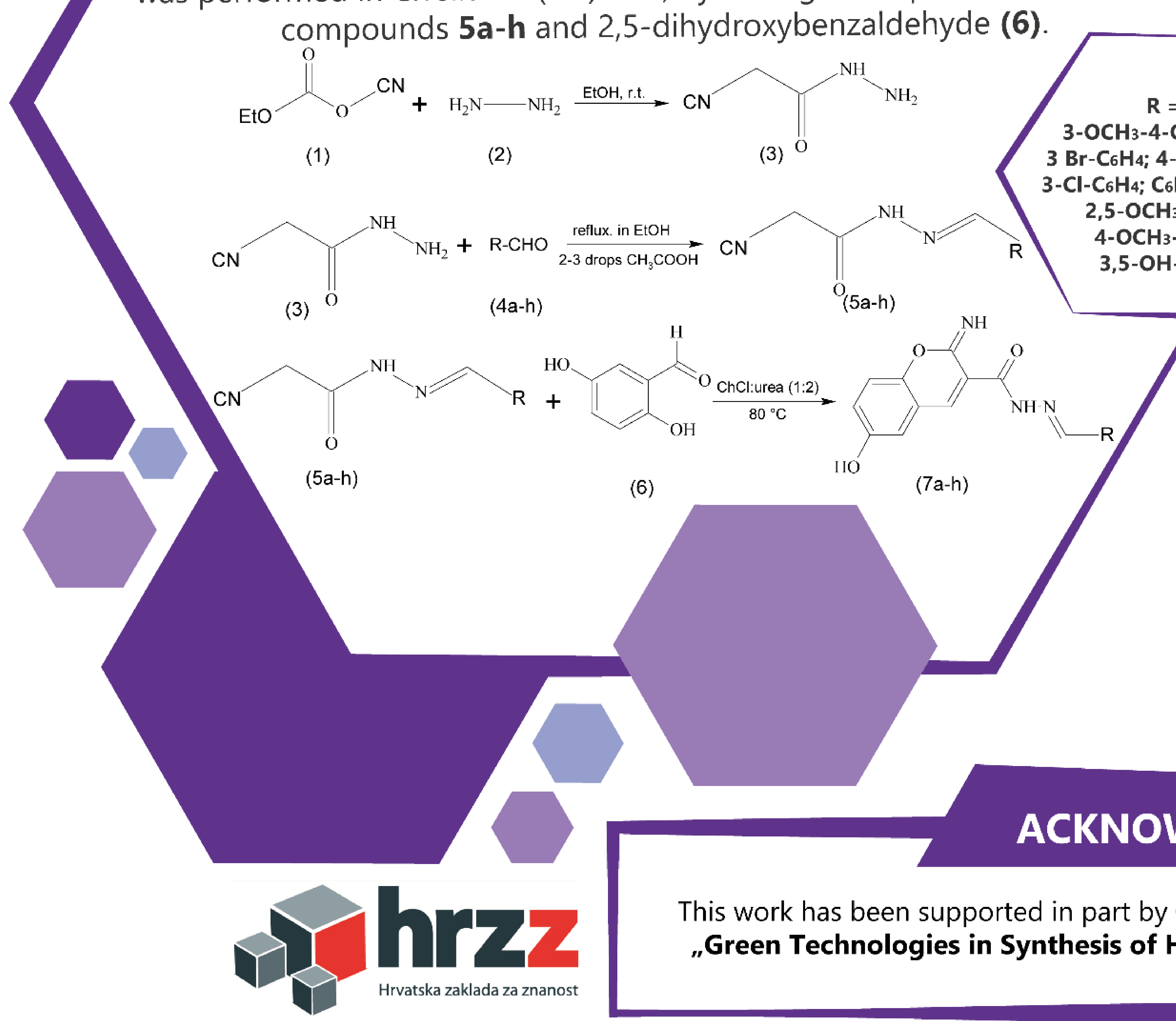
$\mathbf{R}=$
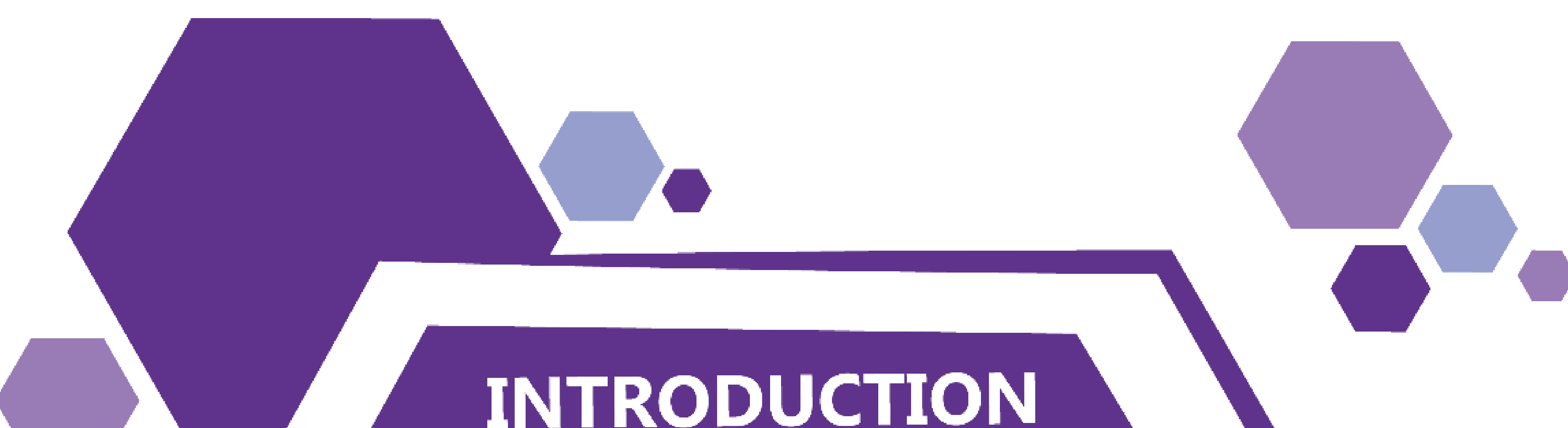

Coumarin and its derivatives as highly bioactive heterocycles possess a wide spectrum of biological pharmacological, biochemical and therapeutic properties, which are strongly structure dependent. Schiff bases bearing coumarin moiety in conjunction with imino group $(-\mathrm{C}=\mathrm{N}-)$ form a significant class of compounds in medicinal and pharma ceutical chemistry.

DESs have proven to be a suitable media for many synthetic path ways. They are generally prepared by mixing a hydrogen bond acceptor (HBA) and one or more hydrogen bond donors

(HBDs) that has the ability to form a eutectic mixture, which shows a significant lower melting point than their respective initial components. DESs are often described as green, biodegradable mixtures

whose properties can be adjusted for various applications using different molar ratios of HBAs and HBDs.

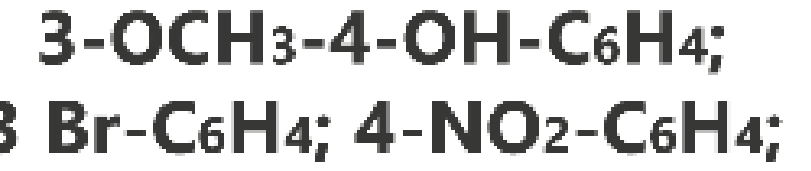
- $\mathrm{Cl}^{-} \mathrm{C}_{6} \mathrm{H}_{4} ; \mathrm{C}_{6} \mathrm{H}_{4}-\mathrm{O}-\mathrm{C}_{6} \mathrm{H}_{4}$; 2,5- $\mathrm{OCH}_{3}-\mathrm{C}_{6} \mathrm{H}_{4}$; 3,5-OH- $\mathrm{C}_{6} \mathrm{H}_{4}$
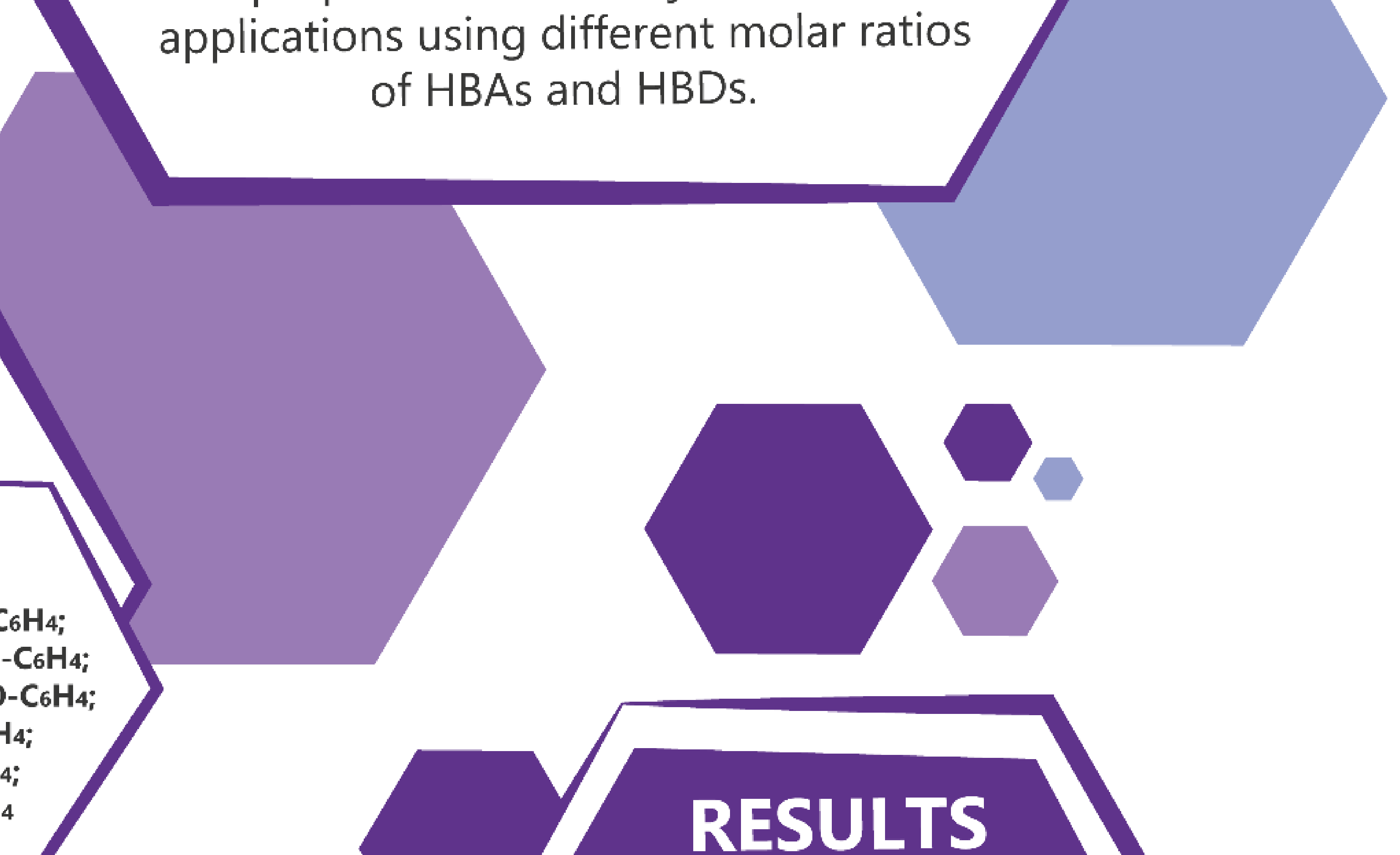